\title{
PERDAGANGAN GULA ILEGAL DI WILAYAH PERBATASAN ENTIKONG INDONESIA DAN MALAYSIA
}

\author{
Elyta \\ Fakultas Ilmu Sosial dan Ilmu Politik Universitas Tanjungpura \\ E-mail: elyta79@yahoo.com
}

\begin{abstract}
ABSTRAK. Tujuan penelitian ingin menganalisa penyebab terjadinya perdagangan gula ilegal antara Indonesia dan Malaysia di wilayah perbatasan Entikong Indonesia dan Malaysia. Jumlah produksi gula di Indonesia yang tidak sebanding dengan jumlah kebutuhan masyarakat menimbulkan terjadinya aktivitas impor gula dari negara Malaysia. Aktivitas impor dalam jangka panjang mengakibatkan negara Indonesia mengalami kerugian dan membuka peluang terjadinya perdagangan gula ilegal. Penelitian ini merupakan penelitian kualitatif, teknik pengumpulan data yang digunakan dengan menggunakan library research dan wawancara. Library research dilakukan dengan mengambil data dari buku, jurnal, koran dan laporan dari instansi terkait, sedangkan wawancara dilakukan dengan mewawancarai informan yang mengetahui dan menangan kasus gula ilegal di perbatasan Entikong Indonesia Dan Malaysia. Berdasarkan hasil penelitian perdagangan ilegal terjadi dikarenakan: 1) penyalahgunaan legislasi Border Trade Agreement (BTA) dengan tujuan mencari keuntungan sebesar-besarnya; 2) harga gula Malaysia lebih murah dibandingkan dengan harga gula Indonesia sehingga terjadi disparasi. Hasil penelitian menunjukkan subsidi gula oleh pemerintah Malaysia sebenarnya untuk kebutuhan rakyatnya, namun oknum agen-agen gula mendistrbusikannya ke Indonesia sehingga subsidi gula pemerintah Malaysia membengkak.
\end{abstract}

Kata kunci: perdagangan internasional, perdagangan gula ilegal, wilayah perbatasan.

\section{ILLEGAL TRADING OF SUGAR IN THE BORDER REGION ENTIKONG INDONESIA AND MALAYSIA}

\begin{abstract}
The purpose of this study wants to analyze the causes of illegal trading of sugar in Entikong Indonesia and Malaysia. Sugar's total production in Indonesia is not proportional to the number of people's needs cause to an activity of sugar imports from Malaysia. Import's activities in the long term cause Indonesia suffered losses and it opens a chance to illegal trading of sugar. This study is a qualitative research, data collection techniques used by using library research and interviews. Library research done by taking data from books, journals, newspapers and reports from relevant agencies. Interviewing was conducted by interviewing informant who knows and handles cases of illegal trading of sugar in Entikong Indonesia and Malaysia border. Based on the results of research on illegal trade of sugar occurs because: 1) abusing action on legislation Border Trade Agreement (BTA) with the goal for maximum profit; 2) Malaysia sugar's price is cheaper compared to Indonesia and then it causes disparation. The results showed the sugar subsidies by the Government of Malaysia is actually for their society, but needs a plurality of agents distributed that sugar to Indonesia, so that sugar subsidies by Government of Malaysia is swell.
\end{abstract}

Key words: international trade, illegal trading of sugar, the border region.

\section{PENDAHULUAN}

Kepentingan nasional suatu negara tidak terlepas pada aktivitas perdagangan internasional dari berbagai negara dan juga menjadi bagian dari politik luar negeri khususnya di wilayah perbatasan. Wilayah perbatasan identik sebagai wilayah yang tertinggal dan terbelakang terutama dalam aspek perekonomian, pendidikan dan infrastuktur (Nugrahaningsih, 2015: 151).

Melalui perdagangan internasional negara dapat menjalankan tugasnya untuk mencukupi dan memperbaiki kebutuhan masyarakat terutama masyarakat yang tinggal di wilayah perbatasan (Wulandari, 2013: 4). Bentuk perdagangan internasional yang marak terjadi salah satunya adalah perdagangan ekspor impor gula.
Disinyalir terjadi dikarenakan harga gula yang melambung tinggi akibat kurangnya persediaan gula untuk memenuhi jumlah konsumsi dan membuka peluang maraknya perdagangan gula ilegal (Pontianak Post, 2 November 2013).

Dengan demikian telah terjadi akumulasi yang tidak sesuai yang diharapkan pada produksi gula di Indonesia. Permintaan gula untuk memenuhi kebutuhan hidup terus bertambah, namun jumlah produksi gula tidak sebanding dengan jumlah permintaan gula, sehingga menjadi peluang bagi produsen gula di luar negeri untuk mengekspor gula ke negara Indonesia, hal tersebut disinyalir menyebabkan fenomena terjadinya perdagangan gula ilegal. Peluang terjadinya perdagangan gula illegal semakin terbuka dengan adanya kesepakatan 
perdagangan lintas batas antara Negara Malaysia dan Negara Indonesia dalam kesepakatan Border Trade Agreement (BTA) pada tahun 1970. Kesepakatan perdagangan lintas batas BTA tersebut berupa pemberian kuota belanja maksimal 600 Ringgit Malaysia setiap bulan perkepala keluarga untuk masyarakat yang tinggal di sekitar perbatasan Indonesia.

Selanjutnya terdapat pula kasus penyelundupan gula ilegal yang terjadi di provinsi Kalimantan Barat tahun 2012-2015 yang disajikan pada tabel 1. berikut ini.

Tabel 1. Kasus Gula Ilegal Provinsi Kalimantan Barat Tahun 2012-2015

\begin{tabular}{|c|c|c|}
\hline No & Kasus & Waktu \\
\hline 1 & $\begin{array}{l}\text { Kepolisian Resor Landak dan } \\
\text { Kepolisian Resor Bengkayang } \\
\text { menemukan 10,4 ton gula putih } \\
\text { ilegal berasal dari Malaysia }\end{array}$ & Februari 2012 \\
\hline 2 & $\begin{array}{l}\text { 1) Sebanyak 2,3 ton gula ilegal } \\
\text { asal Malaysia diamankan } \\
\text { Kepolisian Resor Pontianak. } \\
\text { 2) Sebanyak } 46 \text { karung gula } \\
\text { ilegal dengan berat } 50 \mathrm{~kg} \\
\text { dari Malaysia diamankan } \\
\text { Kepolisian Resor Mempawah. }\end{array}$ & Mei 2012 \\
\hline 3 & $\begin{array}{l}\text { Kepolisian Resor Singkawang } \\
\text { mengamankan } 278 \text { karung gula } \\
\text { ilegal Malaysia ukuran } 50 \mathrm{~kg} \\
\text { dengan total jumlah } 13,8 \text { ton. }\end{array}$ & Juli 2013 \\
\hline 4 & $\begin{array}{l}\text { Sebanyak } 49 \text { karung gula ilegal } \\
\text { asal Malaysia disita oleh Kodim } \\
\text { 1207/BS Pontianak J1. Trans } \\
\text { Kalimantan. }\end{array}$ & April 2014 \\
\hline 5 & $\begin{array}{l}\text { Sebanyak } 75 \text { karung gula pasir } \\
\text { ilegal asal Malaysia diamankan } \\
\text { oleh Kepolisian Resor Sanggau } \\
\text { di Tayan Hulu }\end{array}$ & $\begin{array}{l}\text { September } \\
2015\end{array}$ \\
\hline 6 & $\begin{array}{l}\text { Satuan Tugas Kepolisian Resor } \\
\text { Sambas mengamankan } 3 \text { ton gula } \\
\text { ilegal asal Malaysia di Sajingan }\end{array}$ & $\begin{array}{l}\text { Desember } \\
2015\end{array}$ \\
\hline
\end{tabular}

Sumber: Kepolisian Daerah Provinsi Kalimantan Barat (dalam Islami, 2016:5)

Berdasarkan tabel 1. dapat dilihat maraknya kasus-kasus penyeludupan gula yang terjadi di Provinsi Kalimantan Barat, keberadaan gula ilegal tersebut berasal dari Negara Malaysia. Kasus terakhir penyeludupan gula ilegal pada tahun 2015 terjadi di dua wilayah kabupaten yang memiliki perbatasan yaitu kabupaten Sanggau dan Kabupaten Sambas, sebanyak 75 karung gula ilegal berhasil diamankan oleh Kepolisian Resor Sanggau dan sebanyak 3 ton gula ilegal berhasil diamankan oleh Satuan Tugas Kepolisian Resor Sambas.

Selain itu kasus penanganan kasus penyeludupan gula pasir ilegal di Provinsi Kalimantan Barat sampai dengan bulan Oktober 2016 disajikan pada tabel 2 . berikut ini.

Berdasarkan tabel 2. terlihat kasus penyeludupan gula ilegal terbanyak adalah wilayah Kabupaten Sanggau yang merupakan kabupaten yang memiliki
Tabel 2. Penyeludupan Gula Pasir Ilegal di Provinsi Kalimantan Barat s/d Oktober 2016

\begin{tabular}{lccc}
\hline & Satuan Wilayah & \multicolumn{2}{c}{ Banyaknya Kasus } \\
\cline { 3 - 4 } No & $\begin{array}{c}\text { Penanganan Penyeludupan } \\
\text { Gula }\end{array}$ & Pelaporan & Tuntas \\
\hline 1. & Polisi Resor Mempawah & 2 & 2 \\
2. & Polisi Resor Singkawang & 2 & 1 \\
3. & Polisi Resor Bengkayang & 1 & 1 \\
4. & Polisi Resor Sambas & 1 & 0 \\
5. & Polisi Resor Landak & 3 & 3 \\
6. & Polisi Resor Sanggau & 12 & 5 \\
7. & Polisi Resor Kapuas hulu & 1 & 0 \\
\hline & $\quad$ Jumlah & 22 & 12 \\
\hline
\end{tabular}

Sumber: Biro Operasi Kepolisian Daerah Kalimantan

Barat (2016)

perbatasan yaitu Entikong, berdasarkan hal tersebut maka peneliti tertarik untuk melakukan penelitian tentang penyebab terjadinya perdagangan gula ilegal di wilayah perbatasan Entikong Indonesia dan Malaysia.

\section{METODE}

Artikel ini menggunakan analisa kualitatif dengan menganalisa penyebab terjadinya perdagangan gula ilegal di wilayah perbatasan Entikong Indonesia dan Malaysia. Peneliti mendapatkan data sekunder yaitu buku, jurnal, koran Pontianak Post, laporan dari Kepolisian Daerah Kalimantan Barat. Lebih lanjut wawancara dilakukan dengan Kepala Badan Pembangunan Perbatasan dan Daerah Tertinggal Provinsi Kalimantan Barat, 1 orang Seksi informasi kepabeanan dan cukai Provinsi Kalimantan Barat, Kepala Unit Sub Direktorat 1 Direktorat Reserse Kriminal Kepolisian Daerah Kalimantan Barat, Bupati Kabupaten Sanggau, Kepala Seksi Ekspor dan Impor Dinas Perindustrian Perdagangan Kabupaten Sanggau, Camat Entikong, Kepala Unit Pengelola Pos Pemeriksaan Lintas Batas Entikong, Kepala Bea Cukai Entikong, Kepala Kepolisian Sektor Entikong, 2 orang tokoh masyarakat perbatasan Entikong, 2 orang tokoh masyarakat Malaysia dan 2 orang agen gula Malaysia. Selanjutnya penelitian ini dilakukan di wilayah perbatasan Entikong Indonesia dan Malaysia dengan alasan karena Entikong telah memiliki Pos Lintas Batas Negara, namun disinyalir marak terjadinya perdagangan gula ilegal.

\section{HASIL DAN PEMBAHASAN}

\section{Penyalahgunaan Legislasi Border Trade Agreement (BTA)}

Negara berkembang harus mengantisipasi terjadinya globalisasi yang berpeluang memberikan ancaman terhadap perekonomian. Ancaman tersebut timbul dari pembangunan internasional yang menjadi instrumen negara-negara maju dalam menguasai 
pasar global (Jemadu, 2008: 228). Akibat adanya pasar gobal diindikasi terjadinya perdagangan ilegal. Perdagangan ilegal adalah bentuk kejahatan yang terjadi di lintas batas antar negara (Palimbongan, 2013: 860) penelitian ini menemukan bahwa telah terjadi perdagangan gula ilegal yaitu bentuk kegiatan perdagangan gula yang masuk ke Indonesia dan keluar ke Malaysia atau sebaliknya tidak sesuai dengan kesepakatan perdagangan lintas batas antara Malaysia dan Indonesia yaitu BTA tahun 1970.

Dengan demikian perdagangan gula ilegal adalah pelanggaran prosedur perdagangan lintas batas antar negara dengan tujuan untuk mendapatkan keuntungan sebesar-besarnya.

Perjanjian perdagangan tersebut memuat aturan untuk membatasi jumlah pembelian bahan-bahan, maksimal 600 Ringgit Malaysia setiap bulan perkepala keluarga, namun kebijakan tersebut disalahgunakan oleh para oknum agen gula memanfaatkan masyarakat perbatasan untuk membeli barang-barang Malaysia dengan fasilitas 600 Ringgit Malaysia itu dikumpulkan atau dijual kembali dengan tujuan mendapatkan keuntungan yang lebih banyak. Di bidang politik secara konsep tidak ada kejelekan dari politik namun yang ada adalah praktek politik kotor yang dilakukan oleh oknum-oknum tertentu sehingga terjadi perdagangan ilegal.

Barang-barang yang masuk secara legal menjadi ilegal tidak sesuai dengan kesepakatan perdagangan lintas batas antara Malaysia dan Indonesia dengan disepakatinya BTA tahun 1970. Berdasarkan BTA masyarakat perbatasan Indonesia maksimal bisa membeli barang di Malaysia dengan batasan 600 Ringgit Malaysia perbulan.

Dengan demikian Keberadaan BTA dianggap sebagai "pemecah beton tembok Cina" karena masyarakat perbatasan Indonesia dan Malaysia bebas untuk melakukan perdagangan lintas batas, BTA menjadikan akses perdagangan antara Negara Malaysia dan Negara Indonesia menjadi lebih mudah. Melalui BTA aktivitas perdagangan lintas batas dalam bentuk barang dapat ditangani dengan melegalkan aktivitas mereka berdasarkan perjanjian yang telah disetujui oleh Indonesia dan Malaysia.

BTA adalah suatu perjanjian dengan membuka akses di wilayah perbatasan agar masyarakat memperoleh barang sehingga terbebas dari pajak dengan demikian masyarakat dapat memenuhi kebutuh-an hidupnya sehari-hari. Di dalam BTA memuat aturan untuk membatasi jumlah pembelian barang-barang, maksimal 600 Ringgit Malaysia setiap bulan perkepala keluarga. Perjanjian BTA bertujuan untuk meminimalisir kasus-kasus ilegal yang terjadi dalam perdagangan internasional.

Hasil penelitian menemukan bahwa BTA disalah gunakan oleh para oknum agen gula Indonesia dengan memanfaatkan masyarakat perbatasan Entikong untuk membeli gula dari Malaysia dengan fasilitas 600 Ringgit Malaysia. Gula dikumpulkan atau dijual kembali dengan tujuan mendapatkan keuntungan yang lebih banyak. Adanya manipulasi aturan yang berkaitan dengan kebijakan importir gula dari Malaysia ke Indonesia bertujuan meminimalisir persaingan gula di Indonesia, sehingga menimbulkan kesalahpahaman persepsi mengenai perdagangan ilegal.

Pada kenyataanya tidak ada legislasi yang melarang perdagangan gula secara lintas batas antara negara Indonesia dan negara Malaysia, namun pada dasarnya pembelian gula harus sesuai dengan sistem dan prosedur. Di perbatasan Entikong Terdapat kebijakan dari pemerintah melalui kartu pas lintas batas untuk masyarakat di sekitar perbatasan. Melalui kartu tersebut masyarakat dapat berbelanja ke negara Malaysia untuk memenuhi kebutuhan hidupnya sehari-hari.

Legislasi pembagian kartu pas lintas batas kepada masyarakat digunakan untuk membeli barang-barang yang berasal dari negara Malaysia dengan batas jumlah pembelian gula 600 Ringgit Malaysia dan tidak boleh lebih dari itu. Apabila sudah keluar daerah tersebut maka kesepakatan tersebut tidak berlaku lagi. Ketika sistem itu dibentuk terdapat penyelewengan yang disalah gunakaan oleh oknum-oknum tertentu sehingga terjadilah kasus perdagangan ilegal.

Masyarakat perbatasan Entikong diberikan hak untuk membeli gula import seharga 600 Ringgit Malaysia dalam rangka memenuhi kebutuhan kehidupan seharihari. Apabila melebihi batas yang telah ditetapkan maka dikenakan pajak. Permasalahannya adalah beberapa pihak menyalahgunaan kartu-kartu tersebut dengan tujuan memperoleh keuntungan yang lebih besar.

Hasil penelitian menemukan terdapat 100 kartu pas lintas batas yang disalah gunakan, untuk membeli gula berkisar sampai 60.000 Ringgit Malaysia. Kegiatan inilah yang sebenarnya berbentuk ilegal. Hal tersebut dikarenakan para oknum agen gula takut akan dikenakan pajak jika melebihi batasan yang seharusnya di tetapkan BTA yaitu 600 Ringgit Malaysia

\section{Harga Gula Malaysia Lebih Murah Dibandingkan Dengan Harga Gula Indonesia}

Negara berkembang dibidang perdagangan internasional termasuk negara tertinggal jika dibandingkan dengan negara maju karena negara maju memiliki industri bidang teknologi lebih modern dalam memproduksi barang, sehingga permintaan barang lebih mendominasi di negara maju (Wulandari, 2013: 6). Hasil penelitian menemukan bahwa gula yang berasal dari negara Malaysia dipatok dengan harga yang lebih murah, sehingga masyarakat lebih tertarik mendapatkan harga yang lebih murah. 
Salah satu penyebab harga gula Indonesia lebih mahal adalah minimnya sarana dan prasarana distribusi gula, sehingga biaya distribusi melambung tinggi dan berdampak pada harga gula yang didatangkan dari pulau Jawa. Biaya untuk mendistribusikan gula dari pulau Jawa ke Pontianak sebesar Rp 1000,-- hingga Rp 2.000,per kilogramnya dan pendistribusian gula dari Pontianak ke wilayah perbatasan juga memerlukan biaya, sehingga biaya distribusi gula menjadi dua kali lipat. Menyikapi hal tersebut dibutuhkan peran serta dari Badan Urusan Logistik untuk menyediakan bahan sembako di wilayah perbatasan Entikong Kalimantan Barat dengan harga yang dapat dijangkau oleh masyarakat perbatasan Entikong.

Strategi mengatasi kebutuhan gula di wilayah perbatasan dilakukan Kementrian Perdagangan menunjuk tiga perusahaan yakni PT. Gula Rajawali III, PT. Industri Gula Nusantara dan PT Eka Tunggal Mandiri. Namun, kebijakan tersebut mendapatkan kritikan mengingat perusahaan tersebut berada di wilayah jangkauan yang jauh. Pengusaha gula menyarankan kepada pemerintah agar melegalkan gula di wilayah perbatasan, untuk mengoptimalkan waktu, biaya angkut dan penetapan harga gula di Indonesia (Pontianak post, 16 Mei 2013).

Berikut ini adalah indeks harga gula pasir di Provinsi Kalimantan Barat sampai dengan bulan Oktober tahun 2016 yang disajikan dalam tabel 3. berikut ini.

Tabel 3. Indeks Harga Gula Pasir di Provinsi Kalimantan Barat sampai dengan Oktober 2016

\begin{tabular}{llll}
\hline No & Penjual & $\begin{array}{l}\text { Harga Jual } \\
\text { Gula Lokal }\end{array}$ & Keterangan \\
\hline 1. & $\begin{array}{l}\text { Indeks Tetap Harga } \\
\text { Komersil Divre }\end{array}$ & 11.000 & Non Pajak \\
& Bulog & & \\
2. & Harga Pasaran s/d & $12.900-$ & Include \\
& Oktober 2016 & 13.000 & PPN 10\% \\
\hline
\end{tabular}

Sumber: Direktorat Intelijen Keamanan Kepolisian Daerah

Kalimantan Barat (2016)

Hasil penelitian menemukan bahwagula termasuk dari barang ilegal yang terbanyak karena untung yang di dapatkan dari penjualan gula ilegal lebih banyak dari pada barang lain. Harga gula di Indonesia saat ini sebesar Rp.13.000,- hingga Rp.14.000,- per kilogram dan terendah sebesar Rp.11.000,- per kilogram, sedangkan harga gula yang dijual di negara Malaysia sebesar Rp.9.000,- per kilogramnya. Dapat dilihat selisih harga gula negara Indonesia dan negara malaysia sebesar $\mathrm{Rp}$ 2.000,- hingga Rp.5.000,- Diasumsikan jika membeli gula sebanyak 100 kilogram, maka keuntungan yang diperoleh sebesar Rp.200.000,- hingga Rp.500.000,-

Lebih lanjut hasil penelitian menemukan bahwa penyebab murahnya harga gula Malaysia adalah pemerintah Malaysia telah memberikan subsidi sebesar 2 RinggitMalaysia perkilogram. Setiapkilo gulayang dijual ke rakyat Malaysia disubsidi dengan APBN Malaysia. Pada dasarnya pemerintah Malaysia mensubsidi gula tersebut untuk kebutuhan rakyatnya. Apabila dirupiahkan besar subsidi yang dilakukan oleh pemerintahan Malaysia sebesar 2 Ringgit Malaysia dengan asumsi 2 Ringgit Malaysia dikali Rp. 3.500,- sebesar Rp. 7.000,- Jika gula tersebut didistribusikan ke rakyat Indonesia, maka jumlah subsidi yang dikeluarkan pemerintah Malaysia semakin besar. Jumlah gula yang dipasok oleh agen Indonesia untuk didistribusikan ke Indonesia paling sedikit 10 ton, berarti keuntungan yang diraih oleh oknum agen-agen gula sekitar Rp.70.000.000,- Kejadian ini mengakibatkan keuangan pemerintah Malaysia mengalami kebocoran.

\section{SIMPULAN}

Bentuk perdagangan internasional yang marak terjadi di kawasan perbatasan Entikong Kabupaten Sanggau salah satunya adalah perdagangan ekspor impor gula. Ada dua penyebab yang mendorong terjadinya perdagangan gula ilegal yaitu; (1) legislasi BTA yang disalah gunakan; (2) tingginya harga gula dari Indonesia dibandingkan harga gula dari negara Malaysia.

Peneliti memberi rekomendasi untuk menanggulangi terjadinya perdagangan gulailegalyaitu(1). Perdagangan gula ilegal tentu memberikan kerugian besar terhadap negara, khususnya dalam pertumbuhan ekonomi negara. Sehingga diperlukan kerjasama dari seluruh pihak; (2). Pemberian keringanan dengan memberikan label harga gula agar lebih murah; (3). Peran Badan Urusan Logistik diperlukan untuk diberdayakan sebagai kedudukan penyedia bahan sembako di Kalimantan Barat.

\section{DAFTAR PUSTAKA}

Biro Operasi Kepolisian Daerah Kalimantan Barat, 2016. Penanganan Kasus Kepabeanan Penyeludupan Gula Pasir Ilegal. Pontianak: Laporan.

Direktorat Intelijen Keamanan Kepolisian Daerah Kalimantan Barat. 2016. Indeks Harga Gula Pasir Di Provinsi Kalimantan Barat. Pontianak: Laporan.

Islami, Aulianisyah. 2016. Implementasi Kebijakan Impor Gula di Provinsi Kalimantan Barat. Publika Jurnal Ilmu Administrasi Negara. 5 (2), $1-15$.

Jemadu, Aleksius. 2008. Politik Global dalam Teori dan Praktek. Yogyakarta: Graha Ilmu.

Nugrahaningsih, Nurfitri. 2015. Kerjasama Bilateral Indonesia Malaysia: Studi Tentang Sosek Malindo Dalam Pembangunan Pos Pemeriksaan Lintas Batas Di Jagoi Babang kabupaten Bengkayang Kalimantan Barat. Jurnal Sosiohumaniora, 17 (2), 149- 155. 
Palimbongan, Elvira Febrian. 2013. Upaya Asean Dalam Menanggulangi Perdagangan Dan Peredaran Narkotika Ilegal Di Kawasan Asia Tenggara (2009-2012). Ejournal Ilmu Hubungan Internasional, 1 (3), 857-866.

Pontianak Post. 16 Mei 2013. Ribuan Ton Gula Ilegal Banjiri Pasar Indonesia.
Pontianak Post. 2 November 2013. Gula Langka Picu Inflasi.

Wulandari, SulisEndah. 2013. Hambatan Perdagangan Lintas Batas Antara Masyarakat Indonesia Dengan Masyarakat Timor Leste. Ejournal Ilmu Hubungan Internasional, 1 (1), 1-15. 